\title{
PRODUCTION OF LOW WATER ABSORPTION TILES USING GRANITE REJECTS
}

\author{
Argonz, R. ${ }^{1,}$; Cabral, D. H. P. ${ }^{1}$; Nogueira, R. E. F. Q. ${ }^{1}$; Sasaki, J. M. ${ }^{2}$ \\ ${ }^{1}$ Universidade Federal do Ceará, Departamento de Engenharia Metalúrgica e de Materiais. Campus do Pici, Bloco 729, CEP 60455-760. Forta- \\ leza, CE, Brazil. \\ 2 Universidade Federal do Ceará, Departamento de Física, Campus do Pici, Bloco 922, CEP 60455-760, Fortaleza, CE, Brazil \\ *argonz@ufc.br
}

\begin{abstract}
This work investigates the technical feasibility of using powder rejects from a granite stone for the manufacture of ceramic tiles with low water absorption. The use of such rejects not only reduces the environmental impact, but could also lower the cost of manufacturing . Initially, the waste was ground and sieved. Water was added to form a mass that was molded into prismatic bars by compression. The specimens were dried for 24 hours and sintered for one hour in a muffle furnace at temperatures of $1155,1165,1175,1185$ and $1195^{\circ} \mathrm{C}$. XDR analysis of both the raw material and the sintered parts were carried out . The maximum linear firing shrinkage was $8.5 \%$ and the maximum water absorption detected was lower than $0.5 \%$. Apparent porosity was lower than $1 \%$ for all the samples . The average value for the apparent density was above $2,3 \mathrm{~g} / \mathrm{cm}^{3}$. The modulus of rupture (MOR- 3 point bending) varied from $26 \mathrm{MPa}$ (samples fired at $1155^{\circ} \mathrm{C}$ ) to $33 \mathrm{MPa}$ (samples fired at $1195^{\circ} \mathrm{C}$ ). For microestruture analysis the samples were subjected to attack by hydrofluoric acid and observed by optical microscopy. Test results demonstrate the potential of granite rejects for the manufacturing of low water absorption tiles.
\end{abstract}

